This item was submitted to Loughborough's Research Repository by the author.

Items in Figshare are protected by copyright, with all rights reserved, unless otherwise indicated.

\title{
The absent presence: children's place in narratives of human trafficking
}

\section{PLEASE CITE THE PUBLISHED VERSION}

https://doi.org/10.1111/area.12473

\section{PUBLISHER}

(C) Royal Geographical Society (with the Institute of British Geographers). Published by Wiley

\section{VERSION}

AM (Accepted Manuscript)

\section{PUBLISHER STATEMENT}

This is the peer reviewed version of the following article: BLAZEK, M. and ESSON, J., 2019. The absent presence: children's place in narratives of human trafficking. Area, 51(2), pp. 324-331, which has been published in final form at https://doi.org/10.1111/area.12473. This article may be used for non-commercial purposes in accordance with Wiley Terms and Conditions for Use of Self-Archived Versions.

\section{LICENCE}

CC BY-NC-ND 4.0

\section{REPOSITORY RECORD}

Blazek, Matej, and James Esson. 2018. "The Absent Presence: Children's Place in Narratives of Human Trafficking”. figshare. https://hdl.handle.net/2134/33365. 


\section{The absent presence: children's place in narratives of human trafficking}

\section{Abstract}

This article uses in-depth qualitative data, obtained as part of research examining human trafficking from Slovakia to the United Kingdom, to explore the place of children in human trafficking processes. Rather than foregrounding cases of children as direct subjects of abuse, the article focuses on instances where children are used to control, manipulate and exploit relatives embroiled in human trafficking. We study examples when children are moved across national borders and those when they remain in the home country, and show how in both accounts their (absent) presence constitutes a significant means for facilitating, maintaining and intensifying the exploitation of their adult relatives. Through doing so, the article demonstrates how identifying the distinct spaces and moments within which children appear in narratives of exploitation has the potential to uncover nefarious practices occurring within the human trafficking process, as well as the indirect effects of human trafficking on family dynamics. The article extends conceptual understandings of agency in human trafficking by illustrating how children are simultaneously subjects of exploitation and emplaced through complex channels within the exploitation of others.

Key Words: Agency; Children; Eastern Europe; Exploitation; Human Trafficking; Qualitative 


\section{Introduction}

Human trafficking has become a significant issue in legal and policy debates on contemporary forms of exploitation and human rights abuses (O'Connell Davidson, 2016; Howard, 2017). Children are often a focal point in these discussions, as well as in related critical scholarship regarding the conceptualisation of human trafficking within legal frameworks (Hynes, 2015; O'Connell Davidson, 2011), sociological studies (Boyden and Howard, 2013; O'Connell Davidson, 2013), and popular and/or media representations (Andrijasevic and Mai, 2016; Yea, 2015). This literature is often situated within a wider intellectual movement seeking to (re)theorise relations between borders, human agency and state apparatus. It does so by problematizing the framing of migrants as objects or victims of migration regimes, and instead adopting migrant subjectivities as the starting point for analysis (see for example Esson, 2015a; Huijsmans and Baker, 2012). This article contributes to this scholarship by exploring the place of children in the narratives presented by adults trafficked between Slovakia and the United Kingdom (UK). Through a series of snapshots, we tease out the multitude of relationships and practices through which children's encounters with human trafficking processes emerge, moving away from the focus on children as "direct victims" of human trafficking.

Our main argument is that children's presence in human trafficking can be significant even if they are not direct subjects of exploitation. Their (absent) presence underpins both the exploitative practices of human trafficking and the trafficked adults' resistance and recuperation. We illustrate these points empirically through interviews with adults who experienced human trafficking between Slovakia and the UK (see AUTHORS, 
DATE for more details). Slovakia has recently emerged as a major source country of human trafficking to the UK, yet only a minority of cases referred to authorities are minors (NCA, 2016). Between 2012 and 2015, 45 persons experienced trafficking in the UK and subsequently entered the national support programme in Slovakia but only one was younger than 18 . While this does not mean that minors in this context are not trafficked, such cases are not recorded, and our article therefore explores the relations between the relative absence of children in the human trafficking files and their presence in trafficking narratives.

The next section provides a concise overview of how this article extends recent debates concerning children in the context of human trafficking and exploitation. It also explains our methodology. The remainder of the article is dedicated to our empirical discussion. We conclude by illustrating how intertwining a more relational perspective on children's agency with understandings of human trafficking processes can help transgress the perpetrator/victim dichotomy and decentre the notion of agency beyond such binary links.

\section{Placing children in human trafficking}

The United Nations Protocol to Prevent, Suppress and Punish Trafficking in Persons, Especially Women and Children (UN, 2000) explicitly focuses investigations of human trafficking on children. It is therefore perhaps understandable if narratives of human trafficking emphasise violence against children and unfold from the urgency to combat it. However, portraying children solely as victims of exploitative practices and in need of 
protection constitutes a denial of their agency (O'Connell Davidson, 2011). As development scholars in particular point out, discourses of human trafficking are based on "norms pertaining to the social, cultural, economic and historic context of the West [that] have been extrapolated to form the basis of the international child rights regime" (Howard, 2014, p.557).

Universalist conceptions of "children in need" do not necessarily acknowledge the local and situated contexts of children's lives. For instance, equating children's mobility and activities that are unsupervised or supervised outside the scope of family and the State automatically with child exploitation overlooks the diversity of "historical and economicmoral" (Boyden and Howard, p.365), familial (Beazley, 2015) and peer (Heissler, 2013) relations in which children's experiences evolve and in which children emerge as actors interlinked and interdependent with others. Even the policies intended to protect children from human trafficking might have both protective and punitive effects and rather than simply imposing supervisory measures on children and their social networks, they trigger active responses in the form of resistance and reworking of regulatory regimes (Aufseeser, 2014). Understanding children's place in human trafficking thus requires thinking beyond the perpetrator/victim couplet. It also requires careful considerations of agency when thinking about children, including "ambiguous" notions of agency that disrupt normative and universal conceptions of childhood and adult-child positionalities (Bordonaro and Payne, 2012). This endeavour requires sensitivity given that while there are children throughout the world being subjected to exploitation linked to human trafficking, children are more than passive subjects of violence. They can and do shape their own lives and the lives of others. 
Additionally, portrayals of children as victims of human trafficking play a performative role in which particular children are displaced and replaced by a symbolic notion of childhood (O'Connell Davidson, 2013). The functions of childhood as "a universalising, affective condition" (Kraftl, 2008, p.82), a vehicle of sympathy conditioned upon age (Hörschelmann, 2015) or a spectacle - "a site of accumulation, commodification and desire - in whose name much is done" (Katz, 2008, p.5) have been widely recognised and discussed in the geographical literature. These arguments, suggesting a shift in political discourses and practices from children's experiences to the instrumental deployment of the idea of childhood, relate also to the debates about human trafficking. Yea's research illustrates this through a number of examples, including how the visual images of a "third world girl" as a "muted" victim is put on display in an affective political campaign intended to generate sympathy and support to anti-trafficking campaigns among the privileged adult audience (Yea, 2015). Elsewhere, Yea presents how local anti-trafficking initiatives become enacted through interventions of global campaigners operating with dislocated representations of the child trafficking victim (Yea, 2013).

Without trivialising the violence experienced by children entangled in the exploitative web of human trafficking processes, this paper seeks to avoid a presumptive approach to children as a priori directly victimised by human trafficking and to develop a critical inter-related perspective of what other positions children assume in human trafficking processes. This is in order to interrogate more critically the relationships and practices between traffickers, trafficked persons and social networks, including family, community and formal institutions. We make this feasible by thinking through the following questions; how does children's presence impact on human trafficking processes? And how are children affected by human trafficking beyond direct victimisation? The 
conceptual reframing required to answer these questions offers scope to avoid universalist deployments of the idea of childhood in human trafficking discourses, and instead focus on localised and situated realities evolving from human trafficking processes as they are experienced by both children and adults. Accordingly, opportunities emerge to highlight the relational notion of social agency across the variety of actors, some of whom are rarely put in the spotlight of human trafficking analyses.

We address these questions using a qualitative methodology comprising a set of twentyfour in-depth interviews with a range of actors in Slovakia and the UK, including persons who were trafficked between Slovakia and the UK and subsequently entered a national support programme in Slovakia between 2012 and 2015 (9), support organisations in Slovakia and the UK, community workers in Slovakia and criminal justice agencies (15). Contact with participants was facilitated by a partner organisation $(\mathrm{PO})$ with a long history of post-trafficking support provision in Slovakia. We received full ethical clearance in accordance with social research norms, including voluntary participation, confidentiality and anonymity, before beginning the fieldwork (more in AUTHORS, DATE). All interviews were undertaken in Slovak by the first author but a case worker from the PO acted as a chaperone in some instances.

Although all interview participants were adults, following thematic data analysis of the transcripts, it became apparent that each of the 9 accounts included substantive references to children as part of the human trafficking experience. Our analysis of these interviews highlighted a variety of child-adult relationships within the context of human trafficking and resulted in four themes of children's (absent) presence identified: 
children as motivation, children as leverage, children and post-human trafficking trauma, traffickers' children.

\section{The absent presence: children's “other" places in human trafficking}

Children as motivation

"I wanted to get married, to have better life, you know, for my children."

(Ms Z, Female participant in her 30's)

For Slovaks trafficked to the UK and participating in our research, the predominant reason to move abroad was to alleviate their impoverished condition, pay off a debt or address other forms of economic hardship. For many, the additional reason to take the risk in moving to a country of which they have little knowledge and with no language abilities were care obligations for children and occasionally other family members. For Ms Z, who was lured to the UK with the prospect of marriage to a non-EU citizen for financial reward, her objective "to have better life" intrinsically meant a better life for her children who stayed in Slovakia with her family.

This theme goes beyond the recognition that traffickers manipulate a desire amongst economically vulnerable people to improve their life chances (Esson 2015b; Limoncelli, 2011). Rather, our participants suggested that adults with young children who were in economically precarious positions were specifically targeted by traffickers. In some cases, the traffickers identified and approached people they knew were in urgent need 
of income. In addition to the motivation to provide for them materially, children could themselves become a means of economic benefits. Slovak traffickers were deemed to be cautious of exploiting children directly (for labour or prostitution), due to an awareness of strict and vigilant child protection policies in the UK in comparison with Slovakia. However, the welfare system in the UK, available to Slovak citizens as European Union citizens, provided an incentive and motivation for targeting adult individuals with young children as they would generate additional money through child benefit payments. Ms J, known to her traffickers before they approached her, noted how:

"When I worked [in a local business] in our town, [the traffickers] approached me, said that I could earn better money in England and additionally receive those benefits they give out there. [They knew] That I have three children [eligible for child benefits] and I lived in an old house with my father and wanted to refurbish it, it's a very old house" (Ms J, Female participant in her 30's)

Ms $\mathrm{J}$ was among the few trafficked persons who had a stable job when she was first approached, but it was known within the community that she was looking for ways to increase her income and address her housing situation. She was not approached by the traffickers solely for her economic hardship (as other people in the area would be more plausible candidates) but also because of her bond with the children and motivation to care for them and improve their living conditions and life chances. 
While Ms $\mathrm{J}$ and the traffickers knew each other, there were cases when traffickers recruited among strangers but with a clear goal and expectation to target adults with young children.

"Q: Were [the traffickers] your family or friends?

A: No, no family, [they were] strangers. They approached me at the train station and asked if I could go... their first question was how many children I had, they said I could work but I would need birth certificates, children's passports."

(Mr H, Male participant in his 30's)

$\mathrm{Mr} \mathrm{H}$ was randomly approached at the train station in an adjacent town to where he was staying. While the traffickers' initial question was about his ability to work abroad, the subsequent interrogation turned towards his family situation. Unlike Ms J, Mr H travelled to the UK without his children, but the traffickers were looking to claim child benefits on his behalf, seizing his passport and bank card once he arrived to the UK. The children, despite not being physically present and subject to direct abuse, consequently became central to the manipulative relationship between $\mathrm{Mr} \mathrm{H}$ and his traffickers.

In a couple of cases, it was the presence of trafficked persons' minor siblings and the wider family dynamics that shaped the process of human trafficking. Marriage between two young female participants, Ms A and Ms R, with non-EU citizens in the UK was initially arranged by their families and traffickers in Slovakia. Ms A and Ms R were both 
among the oldest siblings in large families living in poverty where the parents struggled to provide even the basics for all their children. Ms R also had a child of her own. In both families, it was expected that young women should get married and move to their husband's households as soon as possible once they reached adulthood. While Ms A and Ms R's families were oblivious to the actual intentions of the traffickers and subsequent abuse both young women would endure in the UK, they pushed for their daughters to move to the UK to improve the family economic situation and to provide more for their younger siblings.

“[Ms R's parents] didn't tell her anything. Just one night, 11pm, a car came, the parents put her in it, and she was gone. [Other community members] told me they took her to [a nearby town], there she moved to another car, and then straight to England."

(Ms R's community worker)

These snapshots indicate that although children may not figure in the official trafficking statistics, because they were not the direct or primary subjects of exploitation in the trafficking flows between Slovakia and the UK, they provide a motivation for trafficked adults, traffickers and sometimes also trafficked persons' families to initiate and engage in transactions that unwittingly culminate in exploitation. For trafficked persons, economic hardship is the biggest determinant of the move abroad and exposure to the risk, but this becomes more urgent when they have care responsibilities for children. For 
Slovak traffickers, the direct exploitation of children in the UK constitutes an unnecessary risk due to the perception that authorities dedicate more time and resources towards protecting children. This is perhaps why, as highlighted above, although Slovakia has emerged as a major source country for human trafficking to the UK over the last few years, only a handful of cases referred to authorities and resulting in prosecution have involved children. However, exploiting parents' motivations together with a potential secondary benefit of child welfare payments makes adults with young children more appealing to human traffickers than those without children.

Children as leverage and children in the post-trafficking trauma

After being used as motivation to take up an offer of employment, a trafficked person's children might further become involved in the human trafficking process as leverage through being held captive by traffickers. This was not common because, as mentioned above, adults rarely took their children to the UK and traffickers rarely insisted on this as the presence of neglected children might have attracted the attention of social welfare institutions and prevent flexibility in the exploitation of trafficked adults. However, as the following experience of $\mathrm{Ms} \mathrm{J}$ indicates, assuming control of children was a rare but powerful mechanism of coercion over the parents alongside direct physical violence or threat.

"I was trapped, because they had my children and because I would end up on the street otherwise. The children had terrible scratches and bruises, her [the trafficker'] children were beating mine. I could not ask for help because the 
authorities would take my children away automatically. Because of the children I could do nothing... Nothing, nothing, nothing, even if I could speak English... You know what the institutions in England are like - it's enough if the child has a bruise or scratch."

(Ms J, Female participant in her 30's)

Ms J was separated and had no contact with her children while she was sexually exploited in another part of the town. At first, she was physically contained in a building with no opportunity to leave. Later, the traffickers' surveillance lessened, but she was hesitant to leave the place because of fears over her children's safety. The relationship between Ms J and her traffickers was highly manipulative. Her children were being beaten and traffickers threatened to hurt them further, but her concerns were augmented by her perceptions of the UK child protection services system. Ms J's understanding, based on media portrayals in Slovakia and fuelled by the traffickers, was that even if she left her captivity and asked authorities for help, the injuries caused by the traffickers would be attributed to her own negligence and the children would be removed from her custody.

Existing literature on human trafficking usually highlights the experiences of trafficked people with regards to their recruitment, transportation and exploitation (Smith, 2017). However, research is emerging that seeks to understand better the experiences and after effects trafficked people face upon being removed from sites of exploitation (e.g. Richardson et al. 2009; Stanley et al. 2016). In cases where traffickers and trafficked adults came from the same community in Slovakia, children continued to be used as leverage during the post-trafficking stage of police investigation and re-integration. This 
is the case especially with single parents with little support in the community, who might become intimidated by traffickers' threats in relation to their children, even though the threats might not be of physical violence. After Ms J returned to Slovakia, she went through a long period of coping with the trafficking trauma. While she successfully reestablished herself in her home town, found a stable job and accommodation and her children attended the school and had good relationships within the community, she felt unable to tell, especially her younger children, the full story of sexual violence she experienced. In contrast, some of the traffickers who returned to live in the same town were spreading stories of Ms $\mathrm{J}$ working as a prostitute on her own free will in the UK, and one of the most difficult parts of her post-trafficking experience became the task of sheltering her children from these rumours and the associated humiliation she experienced.

"It was unpleasant, of course when I returned to Slovakia, everyone knew it already, because [one of the traffickers] told everyone. When I went to enrol my children to school, I felt that the headteacher was very distant, as if [he thought] I went there voluntary [for prostitution]."

(Ms J, Female participant in her 30's)

Given the psychological and emotional implications that shame had on Ms $\mathrm{J}$ and (indirectly) her children, it was concerning to find that trafficked people who return to Slovakia receive limited social and legal support, and similarly to other contexts 
(Tsutsumi et al. 2008), their mental health needs are largely unaddressed. Therefore, rather than being experienced as an individual trauma, human trafficking affected in numerous ways both the trafficked adults and their families. In this particular case, with no source of institutional psychological support, Ms $\mathrm{J}$ accentuated the aspect of shame associated with her children finding out about her experience, as well as the possible damage to their own mental wellbeing (cf. Ugarte et al. 2004).

$\mathrm{Mr} \mathrm{L}$, in comparison, reflected on the shame induced by failing to meet his family's expectations, and returning from what was supposed to be a lucrative journey to England without any material gains to show for his absence.

"When I arrived in Bratislava [the Slovak capital], then went to [a district town], I wanted to kiss the soil. Slovakia. Happy I was home, free, alive. But what for? My wife expected me to come with money. Family, kids, and I didn't even bring cookies for the children, nothing, all for nothing. I almost cried a river over that."

(Mr L, male participant in his 50's)

The topic of shame and the issue of (returning) migrant's emotional ties and relationships with their children speaks to wider literature on familial relations within migration studies and children's geographies (Beazley et al, 2017; Lindquist, 2004; Moskal and Tyrell, 2016). These studies highlight that children left behind by their transnational migrant parents are often embroiled in community anxieties linked to the emotional economy of transnational migration, including parental shame. In narratives 
like Mr L's, children's absence in the original trafficking story translates into an intense presence in the story of post-trafficking trauma. The reconciliation of painful past experiences with the present recuperative efforts is hampered by parents' emotional ties to their children, the need to protect children from adults' own trauma, and the overarching sense of failure in upholding caring responsibilities. Amplified especially for single parents with little additional social support networks, the emotional relationships with their children constitute both a motivation to move on and re-build their lives and a burden as they re-experience their trauma with regards to the effects it has on the children.

\section{Traffickers' children}

The previous accounts illustrated that relationships between adults and children can be fundamental to the experience of human trafficking even if children do not experience it directly. However, it is not only relationships of trafficked adults and their children as the narratives we analysed briefly highlighted also the rather neglected issue of traffickers' own children. In Slovakia, like elsewhere (Turner and Kelly, 2009), extended family networks among traffickers are essential to the facilitation of human trafficking due to the magnitude of operation and the lack of alternative structures for organized crime. Many participants in this research reported that they came in contact with wider families of their traffickers, including their children. Some participants reported how the children of traffickers were provided a good quality of life, and they brought them to articulate the contrast with their own experiences. For instance, whereas central to Ms J's story was the neglect and abuse experienced by her children, she explained how the young 
children of her traffickers regularly attended school in England and actually participated in the abuse of Ms J's own children. However, other participants reported on neglect, abuse and even trafficking of traffickers' own children, including their solicitation for prostitution and arranged marriages.

"[The female trafficker] sold her daughter, they reported her and [the daughter's father] is now in jail, in England. The daughter went in care, child services took her in Slovakia. But [the trafficker] came home, took her and brought her back [to England]"

(Ms Z, female participant in her 30's)

Children's positions in the dynamic and complex relationships of human trafficking sometimes emerged from situational and fleeting encounters with adults involved in human trafficking, both as exploiters and subjects of violence. The story of $\mathrm{Mr} \mathrm{H}$ and his sister, exemplifies neglect - rather than deliberate abuse for the purpose of economic benefit - that children of their traffickers experienced.

"They had three children... We had to protect them, they did nothing for them, did not cook until my girlfriend made some soup for them at least"

(Mr H, male participant in his 30's) 
This quote from $\mathrm{Mr} \mathrm{H}$, and the preceding discussion, illustrate why our earlier call for more nuanced and relational understandings of agency within conceptualisation of human trafficking is needed. The agency of trafficked persons, and the ways in which this is manipulated and used by traffickers, tends to be oversimplified both in the media and at the policy level; with agency often presented as discrete individuated 'choices' divorced from wider structural conditions, particularly in debates over sex work and forced labour (see Anderson \& Ruhs 2010; O'Connell Davidson, 2015). Yet it is apparent from the narratives above that the agency of trafficked persons should not be dissociated from the diverse contexts and life histories from which they emerge, and that a focus on 'choices' made as a result of coercion and direct exploitation can hide far more than it reveals. A focus on 'choices' made obscures the multitude of relationships and practices through which other actors, in this case children, shape and are shaped by human trafficking processes.

\section{Conclusions}

In this paper we have illustrated how children's presence facilitates processes of human trafficking even if children are not directly trafficked. Their presence can be significant well beyond direct exploitation, and we suggested at least four ways in which it impacts on the shape of human trafficking: through being a motivation for their carers to take the risk and engage in transactions with traffickers; through becoming a leverage for traffickers in the coercion of children's parents; through the emotional dynamics within 
families as trafficked adults cope with the post-trafficking trauma; and as family members of the traffickers themselves, exposed to the various dynamics of human trafficking.

We conclude that children's presence cuts across different spatialities and episodes of human trafficking, and these geographies of children's presence in human trafficking warrant further attention. Our empirical data support the critical claims that exploitation cannot be conceptualised as binary dynamics between the traffickers and the trafficked (see Andrijasevic \& Mai, 2016; Boyden and Howard, 2013; Huijsmans and Baker, 2013). Rather, children highlight the compound web of structural conditions, embodied interactions and social relationships evolving across space and time which necessitate situated responses to children's specific exposure to abuse and exploitation. These responses move beyond the basic conceptualisation of the human trafficking crime. This finding resonates with and extends debates over representation of children within narratives of human trafficking, particularly the performative role that symbolic notions of childhood play in reductive policy responses (Aufseeser, 2014: O'Connell Davidson, 2013)

Furthermore, we wish to take this conceptual recognition and draw attention to children's agency as it stands at the core of the analysis of how human trafficking unfolds. Further to recent geographical scholarship on young people's agency in the context of exploitative relations (Esson, 2015b; van Blerk, 2016), we suggest there is a need to refrain from conceptualising agency as something individually owned and instead employ a more relational perspective in which the capacity to act is derived from the particular sets of relationships one performs (Blazek, 2015). Children's presence 
affects the processes of human trafficking not necessarily through children's individual actions, but rather due to children's roles within social relationships as they emerge across space and time, and as they both underpin and subvert established societal patterns (Bordonaro and Payne, 2012). Highlighting the absent presence of children in the narratives of trafficked adults sheds light on the formation of agency among both trafficking and trafficked adults, as well as others involved in human trafficking dynamics. Our assertion is to focus on the co-dependency in social relationships rather than individual pre-dispositions, and we suggest this focus can be extended analytically to other actors involved in trafficking (and counter-trafficking) processes, such as state agencies, charities, and businesses. 


\section{References}

Andrijasevic, R. and Mai, N. (2016) Trafficking (in) Representations: Understanding the recurring appeal of victimhood and slavery in neoliberal times. Anti-Trafficking Review 7(1), 1-10 DOI: 10.14197/atr.20121771

Aufseeser, D. (2014). "Protecting" street children? Urban revitalization and regulation in Lima, Peru. Urban Geography, 35(6), 870-888.

Beazley, H. (2015) Multiple identities, multiple realities: children who migrate independently for work in Southeast Asia. Children's Geographies, 13(3), 296-309.

Beazley,H., Butt, L. and Ball, J (2017) 'Like it, don't like it, you have to like it’ children's emotional responses to the absence of transnational migrant parents in Lombok, Indonesia, Children's Geographies, early view.

Blazek, M. (2015) Rematerialising Children's Agency: Everyday Practices in a PostSocialist Estate. Policy Press, Bristol.

Bordonaro, L.I. and Payne, R. (2012) Ambiguous agency: critical perspectives on social interventions with children and youth in Africa. Children's Geographies, 10(4), 365-372.

Boyden, J. and Howard, N. (2013) Why does child trafficking policy need to be reformed? The moral economy of children's movement in Benin and Ethiopia. Children's Geographies, 11(3), 354-368.

Esson, J. (2015a) Better Off at Home? Rethinking Responses to Trafficked West African Footballers in Europe, Journal of Ethnic and Migration Studies, 41(3), 512-530. 
Esson, J (2015b) 'You have to try your luck': male Ghanaian youth and the uncertainty of football migration, Environment and Planning A, 47(6), 1383-1397.

Gallagher, A. (2001) Human rights and the new UN protocols on trafficking and migrant smuggling: A preliminary analysis. Human Rights Quarterly, 23(4) 975-1004.

Heissler, K.A. (2013) Rethinking trafficking' in children's migratory processes: the role of social networks in child labour migration in Bangladesh. Children's Geographies, 11(1), 89-101.

Hörschelmann, K. (2015) Divided emotions: children at war. In: Blazek, M. \& Kraftl, P. (Eds) Children's Emotions in Policy and Practice: Mapping and Making Spaces of Childhood. Palgrave, Basingstoke.

Howard, N.P. (2012) A critical appraisal of anti-child trafficking discourse and policy in Southern Benin. Childhood-a Global Journal of Child Research, 19(4), 554-568.

Howard, N. (2017) Child Trafficking, Youth Labour Mobility and the Politics of Protection. Palgrave Macmillan.

Huijsmans, R. and Baker, S. (2012) Child trafficking: 'Worst form' of child labour, or worst approach to young migrants? Development and Change, 43(4), 919-946.

Hynes, P. (2015). No 'Magic Bullets': Children, Young People, Trafficking and Child Protection in the UK. International Migration, 53(4), 62-76.

Katz, C. (2008) Childhood as spectacle: relays of anxiety and the reconfiguration of the child. Cultural Geographies, 15(1), 5-17. 
Kraftl, P. (2008) Young People, Hope, and Childhood-Hope. Space and Culture, 11(2), 81-92.

Limoncelli, S. A. (2009). Human trafficking: Globalization, exploitation, and transnational sociology. Sociology compass, 3(1), 72-91.

Lindquist, J. (2004) Veils and Ecstasy Negotiating Shame in the Indonesian Borderlands, Ethnos, 694, 487-508.

Moskal, M. and Tyrell, N. (2016) Family migration decision-making, step-migration and separation: children's experiences in European migrant worker families. Children's Geographies, 14(4), 453-467.

O'Connell Davidson, J. (2011) Moving children? Child trafficking, child migration, and child rights. Critical social policy, 31(3), 454-477.

O'Connell Davidson, J. (2013) Telling tales: Child migration and child trafficking: Stories of trafficking obscure the realities for migrant children. Child abuse and neglect, 37(12), 1069-1079.

O'Connell Davidson, J. (2015). Modern slavery: The margins of freedom. Palgrave O’Connell Davidson, J. (2016) De-canting 'Trafficking in Human Beings', Re-centring the State The International Spectator 51(1) 58-73

Richardson, D., Poudel, M., \& Laurie, N. (2009). Sexual trafficking in Nepal: constructing citizenship and livelihoods. Gender, Place \& Culture, 16(3), 259-278. 
Smith, D. P, (2017) Population geography I: Human trafficking Progress in Human Geography DOI10.1177/0309132516685196

Stanley, N., Oram, S., Jakobowitz, S., Westwood, J., Borschmann, R., Zimmerman, C., \& Howard, L. M. (2016). The health needs and healthcare experiences of young people trafficked into the UK. Child Abuse \& Neglect, 59, 100-110.

Tsutsumi, A., Izutsu, T., Poudyal, A. K., Kato, S., \& Marui, E. (2008). Mental health of female survivors of human trafficking in Nepal. Social Science \& Medicine, 66(8), 18411847.

Turner, J., Kelly, L. (2009) Trade secrets: intersections between diasporas and crime groups in the constitution of the human trafficking chain. The British Journal of Criminology, 49(2), 184-201.

Ugarte, M.B., Zarate, L., Farley, M. (2004) Prostitution and trafficking of women and children from Mexico to the United States. Journal of Trauma Practice, 2(3-4), 147-165.

UN (2000) Protocol to Prevent, Suppress and Punish Trafficking in Persons, Especially Women and Children. Available:

https://treaties.un.org/doc/Treaties/2000/11/20001115\%201138\%20AM/Ch_XVIII_12_ap.pdf

van Blerk, L. (2016). Livelihoods as relational im/mobilities: Exploring the everyday practices of young female sex workers in Ethiopia. Annals of the American Association of Geographers, 106(2), 413-421. 
Yea, S. (2013) Mobilising the child victim: the localisation of human trafficking in Singapore through global activism. Environment and Planning D-Society \& Space, 31(6), 988-1003.

Yea, S., (2015) Girls on film: Affective politics and the creation of an intimate antitrafficking public in Singapore through film screenings. Political Geography, 45, 45-54. 